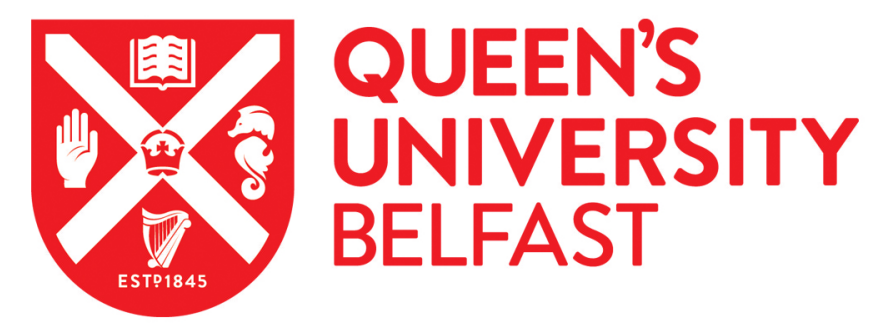

\title{
Examining temporal interactions between loneliness and depressive symptoms and the mediating role of emotion regulation difficulties among UK residents during the COVID-19 lockdown: Longitudinal results from the COVID-19 psychological wellbeing study
}

Groarke, J. M., McGlinchey, E., McKenna-Plumley, P. E., Berry, E., Graham-Wisener, L., \& Armour, C. (2021). Examining temporal interactions between loneliness and depressive symptoms and the mediating role of emotion regulation difficulties among UK residents during the COVID-19 lockdown: Longitudinal results from the COVID-19 psychological wellbeing study. Journal of Affective Disorders, 285, 1-9.

https://doi.org/10.1016/j.jad.2021.02.033

Published in:

Journal of Affective Disorders

Document Version:

Peer reviewed version

Queen's University Belfast - Research Portal:

Link to publication record in Queen's University Belfast Research Portal

\begin{abstract}
Publisher rights
Copyright 2021 Elsevier.

This manuscript is distributed under a Creative Commons Attribution-NonCommercial-NoDerivs License

(https://creativecommons.org/licenses/by-nc-nd/4.0/), which permits distribution and reproduction for non-commercial purposes, provided the author and source are cited.

\section{General rights}

Copyright for the publications made accessible via the Queen's University Belfast Research Portal is retained by the author(s) and / or other copyright owners and it is a condition of accessing these publications that users recognise and abide by the legal requirements associated
\end{abstract} with these rights.

Take down policy

The Research Portal is Queen's institutional repository that provides access to Queen's research output. Every effort has been made to ensure that content in the Research Portal does not infringe any person's rights, or applicable UK laws. If you discover content in the Research Portal that you believe breaches copyright or violates any law, please contact openaccess@qub.ac.uk. 


\section{Introduction}

The general public, academic community, and World Health Organisation have raised concerns about the mental health impact of the COVID-19 crisis (Cowan, 2020; Holmes et al., 2020; WHO, 2020). Physical distancing restrictions and subsequent loss of social interaction, in addition to other challenges associated with living though a global pandemic, represent a significant stressor. The rapid onset of such a stressor may trigger loneliness (Lim et al., 2020) and depressive symptoms (Nolen-Hoeksema et al., 1992). This is concerning as loneliness and depression impact physical health and increase mortality (Holt-Lunstad et al., 2015; Holwerda et al., 2016). Relative to loneliness, objective isolation is a more robust predictor of mortality (Steptoe et al., 2013), whereas loneliness (i.e., subjective isolation) is more robustly associated with depression (Matthews et al., 2016). Successive waves of transmission have led to reintroductions of physical distancing measures to restrict the spread of the virus, including local and regional lockdowns. In the absence of an effective vaccine, mitigation policies are likely to be in place indefinitely. A priority for research is to understand the psychosocial impact of the pandemic and potential mechanisms accounting for any change in mental health symptoms (Holmes et al., 2020). This is in regard to the current COVID-19 global pandemic, and to future-proof the mental health response to future pandemics.

Loneliness is defined as a negative emotional experience resulting from the perception that the quantity or quality of one's social relationships are insufficient (Perlman \& Peplau, 1981). In contrast to the objective nature of social isolation (i.e., having few connections or infrequent contact), loneliness is the unpleasant subjective experience of feeling isolated which has been posited to involve social pain, sadness, and emptiness (Weiss, 1973). Loneliness and depression are distinct but closely related constructs (Mahon et al., 2006; Weeks et al., 1980). Establishing the nature of this relationship has been challenging. The interpersonal theory of depression (Coyne, 1976) and the stress-generation theory (Hammen, 1991) posit that depressive symptoms lead to interpersonal conflicts that damage relationships, thus leading to loneliness. This position has some empirical support from studies of older adulthood (Houtjes et al., 2014) and adolescence (Lasgaard et al., 2011). However, the balance of evidence suggests that either loneliness precedes depression or that the relationship is reciprocal. For older adults, loneliness predicted depressive symptoms 2-12 years later (Cacioppo et al., 2010; Holvast et al., 2015; Jaremka et al., 2014; S. L. Lee et al., 2020). Similar results were found with younger adults (Wei et al., 2005) and adolescents (Qualter et al., 2010). A rapid review of 63 studies concluded that loneliness has a negative impact on the mental health of children, adolescents, and young adults for up to 9 years, with the strongest impact found on 
depression (Loades et al., 2020). Numerous longitudinal studies have found a bidirectional relationship between loneliness and depression (Cacioppo et al., 2006; Domènech-Abella et al., 2019; Hsueh et al., 2019; Santini et al., 2020; Vanhalst, Luyckx, Raes, et al., 2012; Vanhalst, Luyckx, Teppers, et al., 2012). One study found the relationship was stronger with depression as the initial symptom (Hsueh et al., 2019), whereas others found it was stronger and more robust with loneliness as the initial symptom (Domènech-Abella et al., 2019; Vanhalst, Luyckx, Raes, et al., 2012; Vanhalst, Luyckx, Teppers, et al., 2012).

A substantial body of research implicates emotion dysregulation in the development of depression (Aldao et al., 2010; Ehring et al., 2010; Joormann, 2010; Joormann \& Gotlib, 2010; Joormann \& Stanton, 2016; Martin \& Dahlen, 2005). Although loneliness is a negative emotional experience, less research has focused on its link with emotion regulation. Research has found an association between adaptive regulation strategies (i.e., reappraisal) and lower loneliness (Kearns \& Creaven, 2017). Difficulty regulating emotions has been associated with greater loneliness (Wols et al., 2015) and was identified as a risk factor for loneliness during the COVID-19 pandemic (Groarke et al., 2020). There is some evidence that the relationship between loneliness and depressed mood is mediated by the use of maladaptive regulation strategies (e.g., rumination) (Vanhalst, Luyckx, Teppers, et al., 2012; Zawadzki et al., 2013). However, further research is required to understand the role of emotion dysregulation in the development of loneliness, and as a potential mediator of the relationship between loneliness and depression.

\section{Mental health in the COVID-19 pandemic}

Studies carried out during the pandemic have reported slight increases in depression (Canet-Juric et al., 2020; Li et al., 2020), whereas, others found depression and loneliness remained stable (Bu et al., 2020; Fancourt et al., 2020; Wang et al., 2020) or gradually decreased (Mata et al., 2020). Research has also examined the impact of the pandemic by comparing mental health before and after the introduction of mitigation policies. In the UK, distress rose by $8.4 \%$ one month into the lockdown compared to one year earlier (Pierce et al., 2020). Loneliness increased among Dutch older adults, but other mental health outcomes remained stable (van Tilburg et al., 2020). In Central European countries there was a five-fold increase in depressive symptoms, and those with high loneliness had a greater severity of depressive symptoms (Novotny et al., 2020). Moreover, loneliness was the strongest predictor of depression during the pandemic in an Israeli sample (Palgi et al., 2020). There was no significant change in loneliness measured before the outbreak, during the initial stages of the pandemic, or during the lockdown among American adults (Luchetti et al., 2020). Yet other studies 
in the US reported higher loneliness and depression following the onset of the pandemic, and found that change in loneliness was associated with change in depression among older adults (Krendl \& Perry, 2020) and younger adults (C. M. Lee et al., 2020). However, no studies have examined emotion regulation difficulties as a mechanism of this effect between isolation, loneliness, and depression in the context of COVID-19. This is warranted as research suggests the relationship between loneliness and depressed mood is mediated by the use of maladaptive regulation strategies (Zawadzki et al., 2013). Indeed, an ability to effectively regulate one's emotions plays a key role in alleviating the potential negative impact of difficult circumstances many individuals are likely to experience during the pandemic (Restubog et al., 2020).

\section{The current study}

Few longitudinal studies have examined the temporal association between mental health outcomes during the COVID-19 outbreak. Drawing upon pre-pandemic research, it is predicted that the relationship between loneliness and depressive symptoms will be reciprocal, with the possibility of stronger or more robust relationships from loneliness to depressive symptoms. The bidirectional nature of the relationship has been overlooked in existing research during COVID-19. Furthermore, existing studies have focused exclusively on older adults (75 years old on average) or younger adults (18-23 years) in the US, with loneliness and depression assessed before and after but not also during shelter-in-place restrictions (Krendl \& Perry, 2020; C. M. Lee et al., 2020). The current study expands upon this small body of work using structural equation modelling, within a UK context, and with a broader age range of adults. This study will determine the longitudinal relationship between loneliness and depressive symptoms over three timepoints during a period of acute stress (i.e., the four months following the announcement of the UK national lockdown on March $23^{\text {rd }} 2020$ ), and will examine, for the first time, the mediating role of emotion dysregulation in this relationship. Studies carried out prior to the pandemic have typically examined these relationships over prolonged periods (1-14 years), therefore, it is important to determine how associations between loneliness and depressive symptoms may manifest over a briefer timeframe and in a pandemic context. This study addresses key research priorities for the pandemic identified by the academic community, public health experts, and the general public (Cowan, 2020; Holmes et al., 2020; WHO, 2020).

\section{Method}

\section{Design and Procedure}

We conducted a longitudinal structural equation modelling analysis with data from the COVID-19 Psychological Wellbeing Study. Full methodological details of the study are reported elsewhere 
(Armour et al., 2020). The study was approved by the Research Ethics Committee at Queen's University Belfast (Reference: EPS 20_96). Participants were recruited via social media platforms and using a panel of UK residents hosted by Prolific. Prospective participants read a participant information sheet and if they provided informed consent proceeded to the online survey, administered through Qualtrics. Baseline data was collected between March $23^{\text {rd }}$ and April $24^{\text {th }} 2020$ (Time 1). Participants were sent a follow-up survey one month post-baseline (Time 2), and again one month later (Time 3: two months post-baseline). One email reminder was sent to non-responders.

\section{Participants}

There were 2511 responses to the survey. Participants were excluded if they did not provide informed consent, were not resident in the UK, or were under 18 years of age. Responses were also screened for data quality (i.e., not completing any measures, or having a completion time less than half the median completion time), with 522 respondents removed from the dataset (see Figure 1). Of these participants, $98.4 \%$ were eligible for follow-up, that is, they provided valid contact information. $84.8 \%$ of those eligible responded to the follow-up assessment one month after baseline, and $79.1 \%$ responded to the final follow-up. There was an overall attrition rate of $20.9 \%$. There were some significant yet slight differences across sociodemographic factors and baseline scores for those with and without complete data and by recruitment strategy (See supplementary appendix 1). Participants with complete data had slightly lower depressive symptoms, but there were no differences in loneliness or emotion regulation difficulties. Participants recruited through Prolific had greater emotion regulation difficulties, but there were no differences in loneliness or depressive symptoms. 


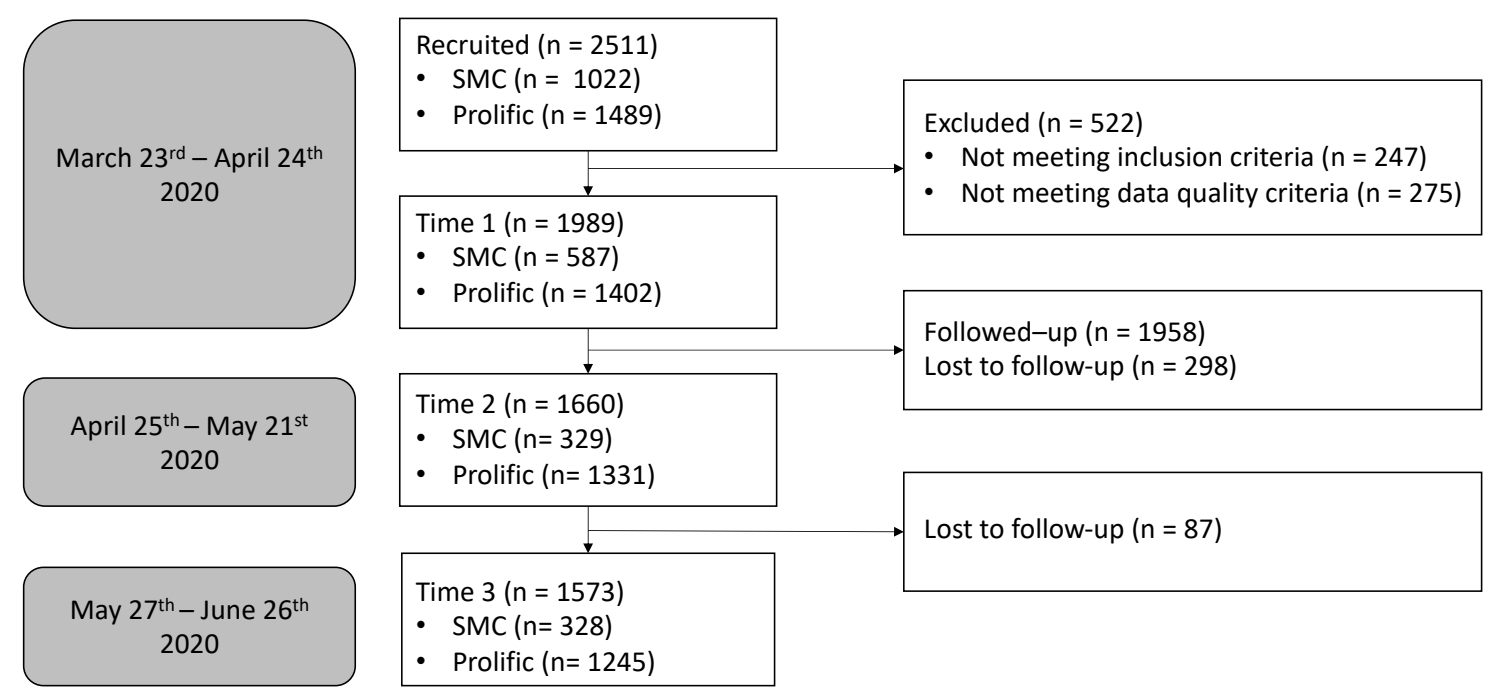

Figure 1. Flowchart of the study sample by recruitment strategy at each timepoint.

Notes; SMC = social media campaign .

\section{Measures}

Loneliness: The UCLA Three-Item Loneliness Scale (Hughes et al., 2004) assessed feelings of loneliness. Participants responded to items such as 'how often do you feel that you lack companionship?'. The items were rated "hardly ever" (0), "some of the time" (1) or "often" (2). Items were summed to produce a total loneliness score. Internal consistency of the measure in the current sample was very high (Cronbach $\alpha \mathrm{T} 1=.82, \mathrm{~T} 2=.85, \mathrm{~T} 3=.88$ ).

Depressive symptoms: The Patient Health Questionnaire (Kroenke et al., 2001) assessed symptoms of major depressive disorder. The 9-item questionnaire measures how often respondents have been bothered by symptoms such as 'Feeling down, depressed, or hopeless'. Response options range from 0 (not at all) to 3 (nearly every day). In the current sample reliability coefficients were high (Cronbach's $\alpha \mathrm{T} 1=.91, \mathrm{~T} 2=.92, \mathrm{~T} 3=.88)$.

Emotion Regulation Difficulties: The Difficulties in Emotion Regulation Scale - Short Form (Kaufman et al., 2016) contains 18 items rated on a 5-point Likert scale. Respondents are asked how often statements like 'When I'm upset, I have difficulty controlling my behaviours' apply to them. The response categories ranged from, 'almost never' (1) to 'almost always' (5). Cronbach's alpha coefficients were high across each measurement time point (Cronbach $\alpha \mathrm{T} 1=.91, \mathrm{~T} 2=.92, \mathrm{~T} 3=.92)$. 
At baseline participants were asked to report their experiences of loneliness and emotion regulation difficulties over the past week and their depressive symptoms over the past two weeks. At Time 2 and Time 3, measures were rephrased to ask participants to reflect on their experiences over the previous month.

\section{Statistical Analysis}

Across study variables, less than $1 \%$ of data was missing at baseline, with $15.8 \%$ missing at Month 1 , and $20.1 \%$ missing at Month 2. Little's MCAR test $\left(\chi^{2}{ }_{(708)}=750.836, p=.128\right)$ showed the data were missing completely at random. Missing data were addressed using the Expectation Maximization algorithm. The 1958 participants who were eligible for follow-up are the focus of all subsequent analyses.

We tested the associations between loneliness, depression symptoms, and emotion regulation difficulty using Pearson's product moment correlations, and descriptive statistics were calculated for all study variables. Cross-lagged structural equation modelling was used to examine the temporal relationships between variables using Amos version 23 (Arbuckle, 2014). Cross-lagged panel models allow for testing bidirectional predictive effects and assessing the relative strength of cross-lagged effects (i.e., the standardised regression coefficients), while also controlling for cross-sectional associations and autoregressive effects. Given this level of statistical control, effect sizes were expected to be small to moderate.

Maximum likelihood estimation was used. Following best practice, a range of indicators were used to assess model fit. Specifically, the chi-square test, the normed chi-square index $(Q)$, the comparative fit index (CFI), the Tucker-Lewis index (TLI), the standardised root mean square residual (SRMR) and the root mean square error of approximation (RMSEA) (Byrne, 2010; Ullman, 2001), with non-significant $\chi^{2}, Q$ values ranging from 2 to 5, CFI and TLI greater than .90, and SRMR and RMSEA less than .08 indicating good model fit (Hu \& Bentler, 1999; Kenny \& McCoach, 2003).

Structural equation modelling was carried out in two stages. The validity of the measurement model was tested first, followed by the validity of the structural model. The measurement model specified included 36 observed variables, that is, the 3 items of the UCLA loneliness measure and the 9 items of the PHQ-9 loading on their 6 respective latent variables (loneliness and depression) at each timepoint (Time 1, Time 2, Time 3) (Model A). Covariances between errors of the repeated measures 
were allowed across timepoints on the basis of high modification indices. In the next step, the autoregressive effects were investigated (Model B). Error terms were co-varied for autoregressive effects, which can be thought of as indicators of the constructs' temporal stability. Then, the structural models examining cross-lagged effects for loneliness and depression separately, with exogenous variables covaried (Models $C$ and $D$ ) and the full reciprocal model, including all covariances, autoregressive paths, and cross-lagged paths (Model E) were assessed. Subsequently, for parsimony, the best fitting model was trimmed by excluding non-significant paths (Model F). Finally, we estimated an expanded model including age as a control variable (Model G) and a modified model including emotion dysregulation as a mediator (Model $\mathrm{H}$ ) and non-significant paths were trimmed from that model (Model I). Due to the complexity of the model and the length of the DERS-SF (18 items), total scores on the DERS-SF were added to the model as 3 observed (i.e., measured) rather than latent variables.

\section{Results}

Baseline characteristics of the study sample are presented in supplementary appendix 1 and in the methodological paper describing the COVID-19 Psychological Wellbeing Study (Armour et al., 2020). In summary, participants $(\mathrm{N}=1958)$ were predominantly Caucasian $(92.7 \%)$ females $(69.8 \%)$ with no religion (57.6\%) residing in England (38\%). Age ranged from 18-87 years ( $M=37.01, S D=12.81$ ). Regarding COVID-19, 58.6\% were self-isolating and 37.4\% were in keyworker positions. Further, $33.8 \%$ of the participants met clinical criteria for probable depression (scores above 10) (Kroenke et al., 2001,2007 ), and $26.8 \%$ of participants were classified as lonely (scores above cut-off of 6 ) (S. L. Lee et al., 2020; Steptoe et al., 2013).

Table 1 presents descriptive statistics and bivariate correlations among variables included in the longitudinal analysis. There were significant associations between loneliness and depression crosssectionally and longitudinally with Pearson's $r$ coefficients ranging from .50 to .59 (all $p<.001$ ). Emotion dysregulation was significantly correlated with loneliness and depression ( $r=.45-.71$, all $p$ $<.001)$, however, correlations with depression were stronger overall $(r=.61-.71$, all $p<.001)$. Across each timepoint age was inversely associated (all $\underline{0}<.001$ ) with loneliness $(r=-.18--.21)$, depressive symptoms ( $r=-.23--.25)$, and difficulties regulating emotions $(r=-.27--.28)$. Gender was not associated with loneliness or difficulties regulating emotions $(p>.05)$. There were weak correlations between gender and depressive symptoms, indicating that symptoms were more severe for females $(r=.09-.11)$. 
Table 1. Means, standard deviations, and Pearson's correlation coefficients between variables included in the longitudinal analyses ( $\mathrm{N}=1958)$.

\begin{tabular}{|c|c|c|c|c|c|c|c|c|c|}
\hline & \multicolumn{3}{|c|}{ Loneliness } & \multicolumn{3}{|c|}{ Depressive Symptoms } & \multicolumn{3}{|c|}{ Emotion Regulation Difficulties } \\
\hline & T1 & $\mathrm{T} 2$ & T3 & T1 & $\mathrm{T} 2$ & T3 & $\mathrm{T} 1$ & $\mathrm{~T} 2$ & T3 \\
\hline$M$ & 5.36 & 5.28 & 5.28 & 7.85 & 7.76 & 7.50 & 42.52 & 41.64 & 41.37 \\
\hline SD & 1.92 & 1.89 & 1.89 & 6.46 & 6.15 & 5.93 & 13.13 & 12.71 & 12.85 \\
\hline \multicolumn{10}{|c|}{ Loneliness } \\
\hline T1 & 1 & & & & & & & & \\
\hline $\mathrm{T} 2$ & $.699^{* *}$ & 1 & & & & & & & \\
\hline T3 & $.699^{* *}$ & $.899^{* *}$ & 1 & & & & & & \\
\hline \multicolumn{10}{|c|}{ Depressive } \\
\hline \multicolumn{10}{|c|}{ Symptoms } \\
\hline T1 & $.552^{* *}$ & $.491^{* *}$ & $.491^{* *}$ & 1 & & & & & \\
\hline T2 & $.523^{* *}$ & $.564^{* *}$ & $.564^{* *}$ & $.796^{* *}$ & 1 & & & & \\
\hline T3 & $.495^{* *}$ & $.594^{* *}$ & $.594^{* *}$ & $.742^{* *}$ & $.850^{* *}$ & 1 & & & \\
\hline \multicolumn{10}{|c|}{ Emotion } \\
\hline \multicolumn{10}{|c|}{ Regulation } \\
\hline \multicolumn{10}{|c|}{ Difficulties } \\
\hline $\mathrm{T} 1$ & $.512^{* *}$ & $.465^{* *}$ & $.465^{* *}$ & $.670^{* *}$ & $.642^{* *}$ & $.614^{* *}$ & 1 & & \\
\hline $\mathrm{T} 2$ & $.467^{* *}$ & $.487^{* *}$ & $.487^{* *}$ & $.626^{* *}$ & $.710^{* *}$ & $.670^{* *}$ & $.817^{* *}$ & 1 & \\
\hline T3 & $.447^{* *}$ & $.509^{* *}$ & $.509^{* *}$ & $.616^{* *}$ & $.665^{* *}$ & $.710^{* *}$ & $.793^{* *}$ & $.860^{* *}$ & 1 \\
\hline
\end{tabular}

Notes; ${ }^{*} \mathrm{p}<.001$; Time 1: Baseline (March 23 $3^{\text {rd }}-$ April $24^{\text {th }}$ ), T2: one month later, T3: two months later. 
Fit of the measurement model (Model A) was acceptable. All standardised regression coefficients (i.e., factor loadings) were above .53 , and statistically significant (all $p<.001$ ). Parameter estimates are presented in Supplementary Appendix 2. There was an improvement in fit indices with the addition of autoregressive effects (Model B). There was further improvement with the addition of cross-lagged effects (Models $\mathrm{C}-\mathrm{E}$ ). The measurement model and the structural models (Models $\mathrm{A}-$ F) were all deemed to have acceptable fit on the basis of CFI, TLI, SRMR and RMSEA criteria (See Table 2). The significant Chi-Square test should not lead to rejection of the model as this is frequently violated when large samples are used (Hu \& Bentler, 1999). Based on fit indices Model F is the best fitting and most parsimonious model, that is, the full reciprocal model with nonsignificant paths trimmed (see Figure 2). The non-significant paths trimmed from Model F were cross-lagged effects between exogenous variables and criterion variables 2 months later. Specifically, loneliness at baseline did not significantly predict depression at Time 3 and depression at baseline did not significantly predict loneliness at Time 3 .

Table 2. Fit indices for alternate models

\begin{tabular}{|c|c|c|c|c|c|c|}
\hline Goodness of fit index: & $\chi^{2}(\mathrm{df})$ & Q & $\mathrm{CFI}$ & SRMR & $\begin{array}{l}\text { RMSEA } \\
(95 \% \mathrm{Cl})\end{array}$ & TLI \\
\hline Suggested value: & $p>.05$ & $2-5$ & $>.90$ & $<.08$ & $<.08$ & $>.90$ \\
\hline $\begin{array}{l}\text { Model A: measurement } \\
\text { model with error terms } \\
\text { covaried across timepoints }\end{array}$ & $\begin{array}{l}4058.49(548) \\
p<.001\end{array}$ & 7.406 & 0.947 & 0.236 & $\begin{array}{l}0.057 \\
(.056, .059)\end{array}$ & 0.932 \\
\hline $\begin{array}{l}\text { Model B: measurement } \\
\text { model with autoregressive } \\
\text { effects }\end{array}$ & $\begin{array}{l}3315.58(549) \\
p<.001\end{array}$ & 6.039 & 0.953 & 0.073 & $\begin{array}{l}0.051 \\
(.049, .052)\end{array}$ & 0.946 \\
\hline $\begin{array}{l}\text { Model C: model B with } \\
\text { cross-lagged effects from } \\
\text { loneliness to depression }\end{array}$ & $\begin{array}{l}3220.96(546) \\
p<.001\end{array}$ & 5.899 & 0.955 & 0.054 & $\begin{array}{l}0.050 \\
(.048, .052)\end{array}$ & 0.948 \\
\hline $\begin{array}{l}\text { Model D: model B with } \\
\text { cross-lagged effects from } \\
\text { depression to loneliness }\end{array}$ & $\begin{array}{l}3253.905(546) \\
p<.001\end{array}$ & 5.960 & 0.954 & 0.060 & $\begin{array}{l}0.050 \\
(.049, .05)\end{array}$ & 0.947 \\
\hline $\begin{array}{l}\text { Model E: model B with all } \\
\text { cross-lagged effects (full } \\
\text { reciprocal model) }\end{array}$ & $\begin{array}{l}3176.150(543) \\
p<.001\end{array}$ & 5.849 & 0.956 & 0.048 & $\begin{array}{l}0.050 \\
(.048, .051)\end{array}$ & 0.948 \\
\hline $\begin{array}{l}\text { Model F: trimmed model } \\
\text { (model } \mathrm{E}=\text { best fitting } \\
\text { model) }\end{array}$ & $\begin{array}{l}3176.24(545) \\
p<.001\end{array}$ & 5.828 & 0.956 & 0.048 & $\begin{array}{l}0.050 \\
(.048, .051)\end{array}$ & 0.949 \\
\hline $\begin{array}{l}\text { Model G: Model F with age } \\
\text { as control variable }\end{array}$ & $\begin{array}{l}3888.829(576) \\
p<.001\end{array}$ & 6.751 & 0.944 & 0.140 & $\begin{array}{l}0.054 \\
(.053, .056)\end{array}$ & 0.936 \\
\hline
\end{tabular}

Notes; $\mathrm{Cl}=$ confidence intervals 
Further inspection of Model F (Figure 2) revealed high temporal stability in loneliness ( $b=.79-.81$ ) and depression ( $b=.73-.85)$ over the first four months of the lockdown. The cross-lagged path between depression and subsequent loneliness was positive and significant from Time 1 to Time 2 ( $b$ $=.09)$ and from Time 2 to Time $3(b=.11)$. The cross-lagged path between loneliness and subsequent depression was also positive and significant at Time $2(b=.17)$ and Time $3(b=.06)$. The model supports the hypothesis that the relationship between loneliness and depression is reciprocal. From baseline to Time 2 the effect of loneliness on depression is stronger $(b=.17)$ than the effect of depression on loneliness $(b=.10)$, but from Time 2 to Time 3 it is weakened $(b=.06)$ while the effect of depression on loneliness remains the same $(b=.11)$.

A multigroup analysis indicated that Model $\mathrm{F}$ was different for males and females $\left(\mathrm{CMIN}_{(74)}=\right.$ $226.711, p<.001)$. When individual paths of the structural model were constrained to be equal for males and females there were no significant differences for any of the autoregressive or crosslagged effects (all $p>.05$ ). This suggests the source of invariance is in the measurement model. A full psychometric validation of the measurement instruments is beyond the scope of this study. Model F was expanded to include age as a control variable (Model G). Older age predicted lower loneliness ( $b$ $=-.23)$ and depression $(b=-.23)$ at baseline, and lower depression at Time $2(b=-.04)$ only. Including age reduced model fit (see Table 2 ) and did not alter the pattern of temporal associations between loneliness and depressive symptoms (see Table 3).

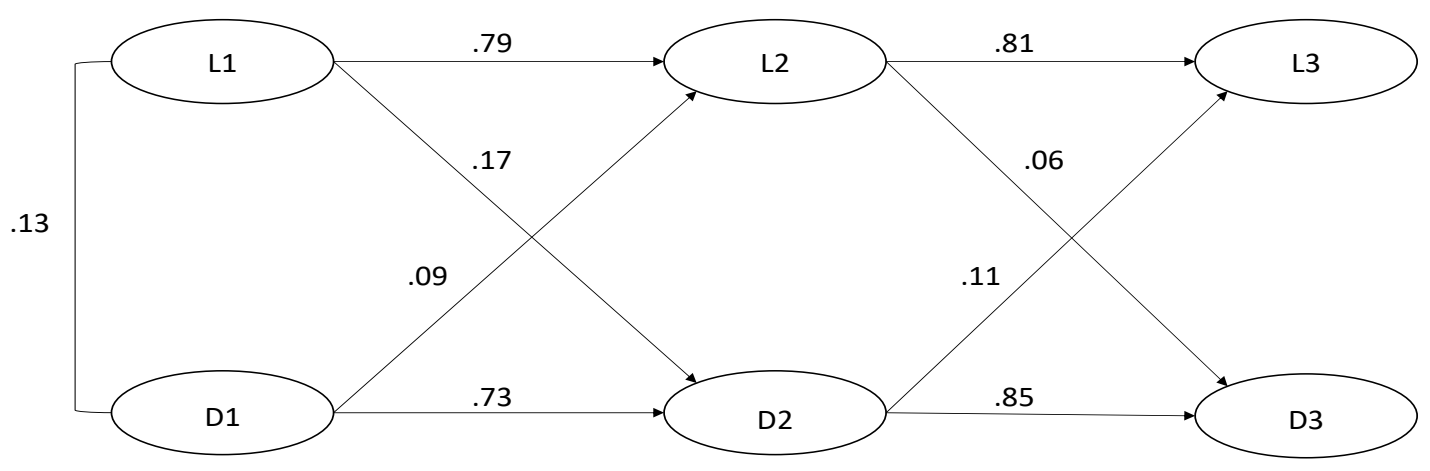

Figure 2. Cross-lagged structural model showing significant paths only.

Notes; all $p<.001 ; L=$ UCLA three-item loneliness scale; D = PHQ-9; Time 1: Baseline (March $23^{\text {rd }}$ April $\left.24^{\text {th }}\right)$, T2: one month later, T3: two months later. 
Are the relationships between loneliness and depression mediated by emotion regulation difficulties?

The fit of the mediation model (Model $\mathrm{H}$ ) was inferior to the best fitting model (Model F), but still represented a good fit of the data $\left(\chi^{2}{ }_{(647)}=4384.016, p<.001 ; \mathrm{Q}=6.776 ; \mathrm{CFI}=.944, \mathrm{TLI}=.936\right.$, SRMR $=.049, \mathrm{RMSEA}=.054[\mathrm{Cl}: .053, .056)$. There was evidence of high temporal stability in emotion dysregulation across the three months of the study $(b=.68-.76)$. The reciprocal association between loneliness and depression was replicated in the modified model, but we did not find support for the prediction that emotion dysregulation mediated the relationship. Loneliness predicted greater difficulties regulating emotion one month later $(b=.06)$, which in turn predicted greater depressive symptoms ( $b=.11)$, and there was a direct effect of depressive symptoms at baseline on subsequent emotion regulation difficulties $(b=.16)$, but no direct effect of emotion regulation difficulties on subsequent loneliness. There was, however, support for bidirectional temporal associations between emotion dysregulation and depression independent of loneliness. Difficulties regulating emotions predicted greater depressive symptoms one month later $(b=.11)$, and depressive symptoms predicted higher emotion regulation difficulties one month later $(b=.13-.16)$. Trimming the non-significant paths resulted in a more parsimonious model but did not improve fit (Model I: $\chi^{2}$ (649) $=4385.208, p<.001 ; \mathrm{Q}=6.757, \mathrm{CFI}=0.944, \mathrm{TLI}=.936, \mathrm{SRMR}=0.049 ; \mathrm{RMSEA}=.054[\mathrm{Cl}:$ $.053, .056])$.

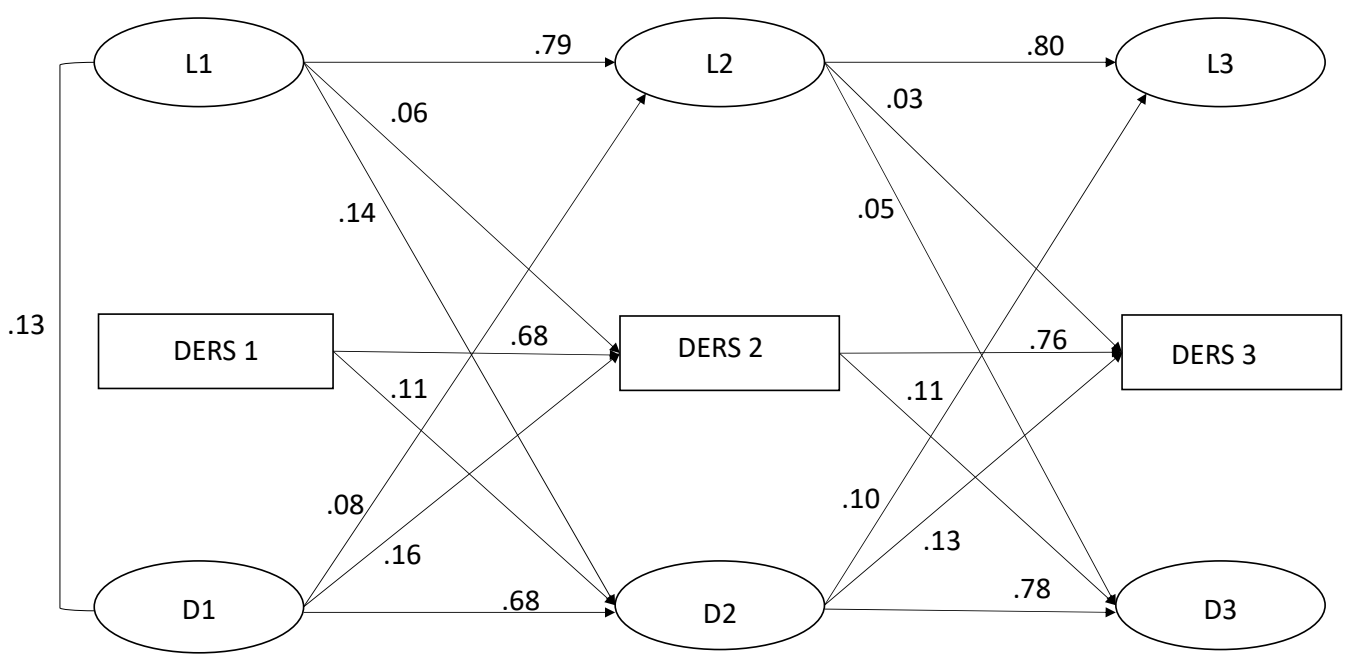

Figure 3. Cross-lagged structural mediation model showing significant paths only.

Notes; all $p<.001 ; \mathrm{L}=$ UCLA three-item loneliness scale; $\mathrm{D}=$ PHQ-9. DERS = Difficulties in Emotion Regulation Scale; Time 1: Baseline (March $23^{\text {rd }}-A$ pril $24^{\text {th }}$ ), T2: one month later, T3: two months later. 
Table 3. Parameter estimates for structural and mediation models

\begin{tabular}{|c|c|c|c|c|c|c|c|c|c|}
\hline & & MODEL B & MODEL C & MODELD & MODEL E & MODEL F & MODEL G & MODEL H & MODEL I \\
\hline Predictor & Outcome & $\beta$ & $\beta$ & $\beta$ & $\beta$ & $\beta$ & $\beta$ & $\beta$ & $\beta$ \\
\hline L1 & $\mathrm{L} 2$ & $.852 * * *$ & $.866 * * *$ & $.761^{* * *}$ & $.795^{* * *}$ & $.795 * * *$ & $.793 * * *$ & $.790 * * *$ & $.795^{* * *}$ \\
\hline D1 & D2 & $.846 * * *$ & $.715^{* * *}$ & $.848 * * *$ & $.734^{* * *}$ & $.734 * * *$ & $.788 * * *$ & $.678 * * *$ & $.679 * * *$ \\
\hline L2 & L3 & $.875 * * *$ & $.879 * * *$ & $.804 * * *$ & $.807^{* * *}$ & $.806 * * *$ & $.815^{* * *}$ & $.805^{* * *}$ & $.806 * * *$ \\
\hline $\mathrm{D} 2$ & D3 & $.884 * * *$ & $.841 * * *$ & $.885 * * *$ & $.847 * * *$ & $.846 * * *$ & $.845 * * *$ & $.784 * * *$ & $.784 * * *$ \\
\hline L1 & D2 & & $.188^{* * *}$ & & $.167^{* * *}$ & $.167^{* * *}$ & $.182 * * *$ & $.145^{* * *}$ & $.146 * * *$ \\
\hline L1 & D3 & & -.006 & & -.006 & & & & \\
\hline L2 & D3 & & $.075^{*}$ & & $.067 *$ & $.063 * * *$ & $.058 * * *$ & $.050 * *$ & $.049 * *$ \\
\hline D1 & L2 & & & $.114^{* * *}$ & $.087 * * *$ & $.086 * * *$ & $.187^{* * *}$ & $.079 * *$ & $.090 * * *$ \\
\hline D1 & L3 & & & -.007 & -.008 & & & & \\
\hline D2 & L3 & & & $.122 * * *$ & $.115^{* * *}$ & $.109 * * *$ & $.103^{* * *}$ & $.101^{* * *}$ & $.109 * * *$ \\
\hline Age & L1 & & & & & & $-.234 * * *$ & & \\
\hline Age & D1 & & & & & & $-.234 * * *$ & & \\
\hline Age & L2 & & & & & & -.013 & & \\
\hline Age & D2 & & & & & & $-.045^{* *}$ & & \\
\hline Age & L3 & & & & & & .009 & & \\
\hline Age & D3 & & & & & & -.006 & & \\
\hline DERS 1 & DERS 2 & & & & & & & $.676^{* * *}$ & $.675^{* * *}$ \\
\hline DERS 2 & DERS 3 & & & & & & & $.761^{* * *}$ & $.761 * * *$ \\
\hline DERS 1 & $\mathrm{~L} 2$ & & & & & & & .020 & \\
\hline DERS 1 & D2 & & & & & & & $.108 * * *$ & $.107^{* * *}$ \\
\hline L1 & DERS 2 & & & & & & & $.056 * *$ & $.057 * *$ \\
\hline D1 & DERS 2 & & & & & & & $.158 * * *$ & $.158 * * *$ \\
\hline DERS 2 & D3 & & & & & & & $.108 * * *$ & $.108 * * *$ \\
\hline DERS 2 & L3 & & & & & & & .012 & \\
\hline L2 & DERS 3 & & & & & & & $.033^{*}$ & $.032 *$ \\
\hline D2 & DERS 3 & & & & & & & $.127^{* * *}$ & $.128^{* * *}$ \\
\hline
\end{tabular}

Notes; ${ }^{* * *} p<.001 * * p<.01 * p<.05 ; \beta=$ standardised beta coefficient; $L=$ UCLA three-item loneliness scale; $D=$ PHQ-9. DERS = Difficulties in Emotion Regulation Scale; Time 1: Baseline (March $23^{\text {rd }}-$ April 24 ${ }^{\text {th }}$ ), T2: one month later, T3: two months later. 


\section{Discussion}

There was high stability in loneliness and depressive symptoms over the first 4 months of the UK lockdown. As predicted, there was a bidirectional positive association between loneliness and symptoms indicative of major depressive disorder. Loneliness predicted higher depressive symptoms one month later, and depressive symptoms predicted higher loneliness one month later. Age was inversely associated with loneliness and depressive symptoms cross-sectionally, but had limited impact over time. Age and gender did not impact the temporal interaction between loneliness and depressive symptoms. The relationship between loneliness and symptoms of depression was not mediated by emotion regulation difficulties. Difficulties regulating emotions and depressive symptoms were related reciprocally. To our knowledge this is the first study to apply longitudinal structural modelling to understand the temporal relationship between key mental health outcomes during the COVID-19 pandemic.

The finding of a reciprocal relationship between loneliness and depressive symptoms is in line with many pre-pandemic studies (Cacioppo et al., 2006; Domènech-Abella et al., 2019; Hsueh et al., 2019; Santini et al., 2020; Vanhalst, Luyckx, Raes, et al., 2012; Vanhalst , Luyckx, Teppers, et al., 2012). The findings are also consistent with US research which demonstrated that loneliness predicted depression during the pandemic (Krendl \& Perry, 2020; C. M. Lee et al., 2020). However, these studies did not simultaneously test the hypothesis that depressive symptoms also predicted loneliness. A recent synthesis of qualitative studies with young people with depression offers a framework for understanding this bidirectional relationship (Achterbergh et al., 2020). Specifically, depressive symptoms, like fatigue and low self-esteem, prompt social withdrawal. Fear of disclosing depression contributes to feelings of alienation. Subsequently, social withdrawal and non-disclosure lead to loneliness, and the negative emotional experience of loneliness contributes to depression.

The current study suggests that although the relationship is bidirectional, loneliness influenced depression less consistently. Parameter estimates reveal that the effect of loneliness on depression is stronger initially but may diminish over time. This aligns with a pre-pandemic study of older adults (Hsueh et al., 2019), but diverges from studies that found the relationship is more robust with loneliness as the initial symptom (Domènech-Abella et al., 2019; Vanhalst, Luyckx, Raes, et al., 2012; Vanhalst et al., 2012). It is also surprising that the cross-lagged paths between loneliness and depression were significant at the subsequent timepoint, but not over longer time periods (two months later). Bidirectional associations have been observed between these variables over much 
longer intervals (i.e., 1-5 years). This suggests that longitudinal patterns may operate differently in the short term or in the context of a novel stressor. The pattern of relations between mental health outcomes may also alter with continued exposure and adaptation to a stressor, or due to changes in the stressor, such as, the relaxing and reintroducing of physical distancing restrictions. Future studies exploring relations between loneliness and depression across shorter timeframes (e.g., days/weeks), or during periods of acute and unpredictable stress are thus warranted.

Contrary to expectations, the longitudinal relationship between loneliness and depressive symptoms was not mediated by difficulties in emotion regulation. It may be that the use of particular regulation strategies (e.g., ability to seek out social support, rumination, or reappraisal), rather than general difficulties regulating one's emotions, mediates the relationship (Zawadzki et al., 2013). Few studies have examined the link between emotion regulation and loneliness, and the current study did not support the idea that they are significantly related in individuals experiencing lockdown due to the COVID-19 pandemic. Although regulation strategies have been associated with loneliness (Wols et al., 2015), and difficulties regulating emotions was a risk factor for loneliness in the initial phase of the lockdown (Groarke et al., 2020), in the current study emotion regulation difficulties did not predict loneliness over time and loneliness had limited impact on emotion dysregulation. However, there was an independent bidirectional association between emotion regulation difficulties and depression, supporting a significant body of pre-pandemic research (Aldao et al., 2010; Ehring et al., 2010; Joormann, 2010; Joormann \& Gotlib, 2010; Joormann \& Stanton, 2016; Martin \& Dahlen, 2005).

There was no significant change in loneliness and depression over the three study timepoints, consistent with some international research (Bu et al., 2020; Fancourt et al., 2020; Luchetti et al., 2020; Wang et al., 2020). Loneliness and depressive symptoms remained stable despite significant shifts in disease-containment policies over the same timeframe. While stricter lockdown measures were in place at Time 1 , from May $8^{\text {th }}$ to $18^{\text {th }}$ (Time 2 ) the UK announced easing of restrictions to allow, for example, outdoor exercise more than once per day and some outdoor gatherings. Notably, average scores on the PHQ-9 were below the threshold indicative of probable depression (Kroenke et al., 2001), and mean scores on the UCLA loneliness measure were also below standard cut-offs for loneliness (Groarke et al., 2020; Steptoe et al., 2013). Despite exposure to a major stressor, most respondents did not suffer significant impairment in mental health. That being said, the four-month timeframe may not capture a delayed impact of the pandemic, which may be mediated by shortterm coping strategies. Further, research has identified more susceptible populations such as the 
LGBTQ community, people in lower socioeconomic positions, minority ethnic groups, and people with disabilities or chronic physical and mental health conditions (lob et al., 2020; Salerno et al., 2020; Wright et al., 2020). Future studies should examine whether the temporal relationships observed in the current study differ among at-risk groups.

This study has important implications for the amelioration of subsyndromal mental health symptoms in the pandemic. The reciprocal relationship observed implies that interventions to reduce loneliness may alleviate depressive symptoms and vice versa. There are four main approaches to reducing loneliness: improving social skills, increasing social support, providing opportunities for social interaction, and addressing maladaptive social cognitions. Meta-analytic and systematic review evidence suggests that interventions that modify social cognitions are most effective (Jarvis et al., 2020; Ma et al., 2020; Masi et al., 2011). For mild-moderate symptoms of depression, clinical guidelines recommend low-intensity psychosocial interventions (NICE, 2009), such as low-intensity Cognitive Behavioural Therapy (CBT) a form of guided self-help that can be facilitated remotely. Online and telephone-based delivery of interventions can reduce depression (Gilbody et al., 2017; Lawn et al., 2019) and loneliness (Bouwman et al., 2017; Weinert et al., 2008), which is encouraging given the pandemic context. Clinical guidelines for treatment of moderate depressive symptoms also recommend physical activity (NICE, 2009). Reviews have concluded that walking and exercise reduce depressive symptoms (Robertson et al., 2012; Stathopoulou et al., 2006), as well as, loneliness (Hwang et al., 2019; Pels \& Kleinert, 2016). Therefore, public health approaches that emphasise increasing physical activity may be particularly helpful for mitigating the mental health impact of the pandemic. Low intensity CBT that addresses social cognitions may also be of benefit. Treatments for depressive symptoms that address emotion regulation difficulties such as Dialectical Behaviour Therapy may be helpful, and adding emotion regulation skills training did improve the efficacy of CBT for major depression (Berking et al., 2013). However, a concurrent focus on loneliness may be necessary to fully address the psychosocial impact of the pandemic.

\section{Strengths and Limitations}

Strengths of the study include the large sample size, the use of validated measures, and the longitudinal design which permitted the examination of temporal relationships and mediation. This study addresses a gap in the research regarding associations between key mental health outcomes in the early stages of the lockdown in a UK context. However, limitations are acknowledged. The sample was not representative, males and older age groups were underrepresented (Armour et al., 2020). Although the psychometric properties of the measures used are well-established (Hughes et 
al., 2004; Kaufman et al., 2016; Kroenke et al., 2001), clinical interviews may have been superior (Levis et al., 2019), but would be unfeasible given the large sample size. Consistent with other studies, loneliness, depression, and emotion dysregulation were stable during the lockdown. There was no pre-pandemic assessment, thereby limiting the conclusions that can be drawn regarding the mental health impact of the COVID-19 crisis. However, that was not the primary objective of the current study. The longitudinal design allows us to determine the temporal relationship between variables, not the causal relationship. Alternative explanations for the association cannot be ignored, for example loneliness and depression may share a common cause not measured in this study. The model was a good fit of the data. As with all structural equation models there may be alternative models that also fit the data equally well, that include other variables and covariates not accounted for in this structural model. Previous research, however, has not found the relationship between loneliness and depression to be significantly impacted by demographics, physical health, or related variables like perceived stress, social isolation, or social support (Cacioppo et al., 2010; Hsueh et al., 2019; S. L. Lee et al., 2020). Confidence in the structural model is enhanced, in that it was initially grounded in empirical research and theory.

\section{Conclusion}

Despite concerns about the negative impact of the pandemic on mental health, findings of the current study suggest that, on average, loneliness and depressive symptoms were mild-moderate and remained stable over the first four months of the UK lockdown. Results demonstrate that feelings of loneliness were positively associated with subsequent depressive symptoms, and that depressive symptoms were also positively associated with subsequent feelings of loneliness. Difficulties in emotion regulation predicted higher depression symptoms and vice versa, but difficulty regulating emotions did not mediate the relationship between loneliness and depression. The findings suggest that loneliness should be considered a potentially important part of case conceptualisation and formulation for individuals presenting with depressive symptoms during this time. Additionally, a measure to screen for loneliness could support assessment and identify those at-risk. Clinical efforts to improve mental health during the pandemic could focus on interventions that target either loneliness, or depression, or both. Such approaches include increasing physical activity or low-intensity cognitive therapies delivered remotely. 


\section{References}

Achterbergh, L., Pitman, A., Birken, M., Pearce, E., Sno, H., \& Johnson, S. (2020). The experience of loneliness among young people with depression: A qualitative meta-synthesis of the literature. BMC Psychiatry, 20(1), 415. https://doi.org/10.1186/s12888-020-02818-3

Aldao, A., Nolen-Hoeksema, S., \& Schweizer, S. (2010). Emotion-regulation strategies across psychopathology: A meta-analytic review. Clinical Psychology Review, 30(2), 217-237. https://doi.org/10.1016/j.cpr.2009.11.004

Arbuckle, J. L. (2014). Amos (Version 24) [Computer software]. IBM SPSS.

Armour, C., McGlinchey, E., Butter, S., McAloney-Kocaman, K., \& McPherson, K. E. (2020). The COVID-19 Psychological Wellbeing Study: Understanding the Longitudinal Psychosocial Impact of the COVID-19 Pandemic in the UK; a Methodological Overview Paper. Journal of Psychopathology and Behavioral Assessment, 1-17. https://doi.org/10.1007/s10862-02009841-4

Berking, M., Ebert, D., Cuijpers, P., \& Hofmann, S. G. (2013). Emotion Regulation Skills Training Enhances the Efficacy of Inpatient Cognitive Behavioral Therapy for Major Depressive Disorder: A Randomized Controlled Trial. Psychotherapy and Psychosomatics, 82(4), 234245. https://doi.org/10.1159/000348448

Bouwman, T. E., Aartsen, M. J., van Tilburg, T. G., \& Stevens, N. L. (2017). Does stimulating various coping strategies alleviate loneliness? Results from an online friendship enrichment program. Journal of Social and Personal Relationships, 34(6), 793-811. https://doi.org/10.1177/0265407516659158

Bu, F., Steptoe, A., \& Fancourt, D. (2020). Loneliness during lockdown: Trajectories and predictors during the COVID-19 pandemic in 35,712 adults in the UK. MedRxiv, 2020.05.29.20116657. https://doi.org/10.1101/2020.05.29.20116657

Byrne, B. M. (2010). Structural Equation Modeling with AMOS: Basic Concepts, Applications, and Programming, 2nd Edn. New York, NY: Routledge.

Cacioppo, J. T., Hawkley, L. C., \& Thisted, R. A. (2010). Perceived Social Isolation Makes Me Sad: Five Year Cross-Lagged Analyses of Loneliness and Depressive Symptomatology in the Chicago Health, Aging, and Social Relations Study. Psychology and Aging, 25(2), 453-463. https://doi.org/10.1037/a0017216

Cacioppo, J. T., Hughes, M. E., Waite, L. J., Hawkley, L. C., \& Thisted, R. A. (2006). Loneliness as a specific risk factor for depressive symptoms: Cross-sectional and longitudinal analyses. Psychology and Aging, 140-151. 
Canet-Juric, L., Andrés, M. L., del Valle, M., López-Morales, H., Poó, F., Galli, J. I., Yerro, M., \& Urquijo, S. (2020). A Longitudinal Study on the Emotional Impact Cause by the COVID-19 Pandemic Quarantine on General Population. Frontiers in Psychology, 11. https://doi.org/10.3389/fpsyg.2020.565688

Cowan, K. (2020). Survey results: Understanding people's concerns about the mental health impacts of the COVID-19 pandemic. Academy of Medical Sciences and MQ Mental Health report. https://acmedsci.ac.uk/file-download/99436893

Coyne, J. C. (1976). Toward an interactional description of depression. Psychiatry, 39(1), 28-40.

Domènech-Abella, J., Mundó, J., Haro, J. M., \& Rubio-Valera, M. (2019). Anxiety, depression, loneliness and social network in the elderly: Longitudinal associations from The Irish Longitudinal Study on Ageing (TILDA). Journal of Affective Disorders, 246, 82-88. https://doi.org/10.1016/j.jad.2018.12.043

Ehring, T., Tuschen-Caffier, B., Schnülle, J., Fischer, S., \& Gross, J. J. (2010). Emotion regulation and vulnerability to depression: Spontaneous versus instructed use of emotion suppression and reappraisal. Emotion, 10(4), 563-572. https://doi.org/10.1037/a0019010

Fancourt, D., Steptoe, A., \& Bu, F. (2020). Trajectories of depression and anxiety during enforced isolation due to COVID-19: Longitudinal analyses of 36,520 adults in England. MedRxiv, 2020.06.03.20120923. https://doi.org/10.1101/2020.06.03.20120923

Gilbody, S., Brabyn, S., Lovell, K., Kessler, D., Devlin, T., Smith, L., Araya, R., Barkham, M., Bower, P., Cooper, C., Knowles, S., Littlewood, E., Richards, D. A., Tallon, D., White, D., Worthy, G., \& Collaborative, on behalf of the R. (2017). Telephone-supported computerised cognitivebehavioural therapy: REEACT-2 large-scale pragmatic randomised controlled trial. The British Journal of Psychiatry, 210(5), 362-367. https://doi.org/10.1192/bjp.bp.116.192435

Groarke, J. M., Berry, E., Graham-Wisener, L., McKenna-Plumley, P. E., McGlinchey, E., \& Armour, C. (2020). Loneliness in the UK during the COVID-19 pandemic: Cross-sectional results from the COVID-19 Psychological Wellbeing Study. PLOS ONE, 15(9), e0239698. https://doi.org/10.1371/journal.pone.0239698

Hammen, C. (1991). Generation of stress in the course of unipolar depression. Journal of Abnormal Psychology, 100(4), 555-561. https://doi.org/10.1037//0021-843x.100.4.555

Holmes, E. A., O'Connor, R. C., Perry, V. H., Tracey, I., Wessely, S., Arseneault, L., Ballard, C., Christensen, H., Silver, R. C., Everall, I., Ford, T., John, A., Kabir, T., King, K., Madan, I., Michie, S., Przybylski, A. K., Shafran, R., Sweeney, A., ... Bullmore, E. (2020). Multidisciplinary 
research priorities for the COVID-19 pandemic: A call for action for mental health science. The Lancet Psychiatry, 7(6), 547-560. https://doi.org/10.1016/S2215-0366(20)30168-1 Holt-Lunstad, J., Smith, T. B., Baker, M., Harris, T., \& Stephenson, D. (2015). Loneliness and Social Isolation as Risk Factors for Mortality: A Meta-Analytic Review. Perspectives on Psychological Science, 10(2), 227-237. https://doi.org/10.1177/1745691614568352

Holvast, F., Burger, H., de Waal, M. M. W., van Marwijk, H. W. J., Comijs, H. C., \& Verhaak, P. F. M. (2015). Loneliness is associated with poor prognosis in late-life depression: Longitudinal analysis of the Netherlands study of depression in older persons. Journal of Affective Disorders, 185, 1-7. https://doi.org/10.1016/j.jad.2015.06.036

Holwerda, T. J., Tilburg, T. G. van, Deeg, D. J. H., Schutter, N., Van, R., Dekker, J., Stek, M. L., Beekman, A. T. F., \& Schoevers, R. A. (2016). Impact of loneliness and depression on mortality: Results from the Longitudinal Ageing Study Amsterdam. The British Journal of Psychiatry, 209(2), 127-134. https://doi.org/10.1192/bjp.bp.115.168005

Houtjes, W., Meijel, B. van, Ven, P. M. van de, Deeg, D., Tilburg, T. van, \& Beekman, A. (2014). The impact of an unfavorable depression course on network size and loneliness in older people: A longitudinal study in the community. International Journal of Geriatric Psychiatry, 29(10), 1010-1017. https://doi.org/10.1002/gps.4091

Hsueh, Y.-C., Chen, C.-Y., Hsiao, Y.-C., \& Lin, C.-C. (2019). A longitudinal, cross-lagged panel analysis of loneliness and depression among community-based older adults. Journal of Elder Abuse \& Neglect, 31(4-5), 281-293. https://doi.org/10.1080/08946566.2019.1660936

Hu, L., \& Bentler, P. M. (1999). Cutoff criteria for fit indexes in covariance structure analysis: Conventional criteria versus new alternatives. Structural Equation Modeling: A Multidisciplinary Journal, 6(1), 1-55. https://doi.org/10.1080/10705519909540118

Hughes, M. E., Waite, L. J., Hawkley, L. C., \& Cacioppo, J. T. (2004). A Short Scale for Measuring Loneliness in Large Surveys: Results From Two Population-Based Studies. Research on Aging, 26(6), 655-672. https://doi.org/10.1177/0164027504268574

Hwang, J., Wang, L., Siever, J., Medico, T. D., \& Jones, C. A. (2019). Loneliness and social isolation among older adults in a community exercise program: A qualitative study. Aging \& Mental Health, 23(6), 736-742. https://doi.org/10.1080/13607863.2018.1450835

lob, E., Steptoe, A., \& Fancourt, D. (2020). Abuse, self-harm and suicidal ideation in the UK during the COVID-19 pandemic. The British Journal of Psychiatry, 217(4), 543-546. https://doi.org/10.1192/bjp.2020.130

Jaremka, L. M., Andridge, R. R., Fagundes, C. P., Alfano, C. M., Povoski, S. P., Lipari, A. M., Agnese, D. M., Arnold, M. W., Farrar, W. B., Yee, L. D., Carson, W. E., Bekaii-Saab, T., Martin, E. W., 
Schmidt, C. R., \& Kiecolt-Glaser, J. K. (2014). Pain, Depression, and Fatigue: Loneliness as a Longitudinal Risk Factor. Health Psychology : Official Journal of the Division of Health Psychology, American Psychological Association, 33(9), 948-957. https://doi.org/10.1037/a0034012

Jarvis, M.-A., Padmanabhanunni, A., Balakrishna, Y., \& Chipps, J. (2020). The effectiveness of interventions addressing loneliness in older persons: An umbrella review. International Journal of Africa Nursing Sciences, 12, 100177. https://doi.org/10.1016/j.ijans.2019.100177 Joormann, J. (2010). Cognitive Inhibition and Emotion Regulation in Depression. Current Directions in Psychological Science, 19(3), 161-166. https://doi.org/10.1177/0963721410370293 Joormann, J., \& Gotlib, I. H. (2010). Emotion regulation in depression: Relation to cognitive inhibition. Cognition and Emotion, 24(2), 281-298. https://doi.org/10.1080/02699930903407948

Joormann, J., \& Stanton, C. H. (2016). Examining emotion regulation in depression: A review and future directions. Behaviour Research and Therapy, 86, 35-49. https://doi.org/10.1016/j.brat.2016.07.007

Kaufman, E. A., Xia, M., Fosco, G., Yaptangco, M., Skidmore, C. R., \& Crowell, S. E. (2016). The Difficulties in Emotion Regulation Scale Short Form (DERS-SF): Validation and replication in adolescent and adult samples. Journal of Psychopathology and Behavioral Assessment, 38(3), 443-455. https://doi.org/10.1007/s10862-015-9529-3

Kearns, S. M., \& Creaven, A.-M. (2017). Individual differences in positive and negative emotion regulation: Which strategies explain variability in loneliness? Personality and Mental Health, 11(1), 64-74. https://doi.org/10.1002/pmh.1363

Kenny, D. A., \& McCoach, D. B. (2003). Effect of the Number of Variables on Measures of Fit in Structural Equation Modeling. Structural Equation Modeling: A Multidisciplinary Journal, 10(3), 333-351. https://doi.org/10.1207/S15328007SEM1003_1

Krendl, A. C., \& Perry, B. L. (2020). The Impact of Sheltering in Place During the COVID-19 Pandemic on Older Adults' Social and Mental Well-Being. The Journals of Gerontology Series B: Psychological Sciences and Social Sciences. https://doi.org/10.1093/geronb/gbaa110

Kroenke, K., Spitzer, R. L., \& Williams, J. B. W. (2001). The PHQ-9. Journal of General Internal Medicine, 16(9), 606-613. https://doi.org/10.1046/j.1525-1497.2001.016009606.x

Kroenke, K., Spitzer, R. L., Williams, J. B. W., Monahan, P. O., \& Löwe, B. (2007). Anxiety disorders in primary care: Prevalence, impairment, comorbidity, and detection. Annals of Internal Medicine, 146(5), 317-325. https://doi.org/10.7326/0003-4819-146-5-200703060-00004 
Lasgaard, M., Goossens, L., \& Elklit, A. (2011). Loneliness, Depressive Symptomatology, and Suicide Ideation in Adolescence: Cross-Sectional and Longitudinal Analyses. Journal of Abnormal Child Psychology, 39(1), 137-150. https://doi.org/10.1007/s10802-010-9442-x

Lawn, S., Huang, N., Zabeen, S., Smith, D., Battersby, M., Redpath, P., Glover, F., Venning, A., Cameron, J., \& Fairweather-Schmidt, K. (2019). Outcomes of telephone-delivered lowintensity cognitive behaviour therapy (LiCBT) to community dwelling Australians with a recent hospital admission due to depression or anxiety: MindStep ${ }^{\mathrm{TM}}$. BMC Psychiatry, 19. https://doi.org/10.1186/s12888-018-1987-1

Lee, C. M., Cadigan, J. M., \& Rhew, I. C. (2020). Increases in Loneliness Among Young Adults During the COVID-19 Pandemic and Association With Increases in Mental Health Problems. Journal of Adolescent Health, 67(5), 714-717. https://doi.org/10.1016/j.jadohealth.2020.08.009

Lee, S. L., Pearce, E., Ajnakina, O., Johnson, S., Lewis, G., Mann, F., Pitman, A., Solmi, F., Sommerlad, A., Steptoe, A., Tymoszuk, U., \& Lewis, G. (2020). The association between loneliness and depressive symptoms among adults aged 50 years and older: A 12-year population-based cohort study. The Lancet Psychiatry. https://doi.org/10.1016/S2215-0366(20)30383-7

Levis, B., Benedetti, A., \& Thombs, B. D. (2019). Accuracy of Patient Health Questionnaire-9 (PHQ-9) for screening to detect major depression: Individual participant data meta-analysis. BMJ, 365. https://doi.org/10.1136/bmj.11476

Li, H. Y., Cao, H., Leung, D. Y. P., \& Mak, Y. W. (2020). The Psychological Impacts of a COVID-19 Outbreak on College Students in China: A Longitudinal Study. International Journal of Environmental Research and Public Health, 17(11), 3933. https://doi.org/10.3390/ijerph17113933

Lim, M. H., Holt-Lunstad, J., \& Badcock, J. C. (2020). Loneliness: Contemporary insights into causes, correlates, and consequences. Social Psychiatry and Psychiatric Epidemiology, 55(7), 789791. https://doi.org/10.1007/s00127-020-01891-z

Loades, M. E., Chatburn, E., Higson-Sweeney, N., Reynolds, S., Shafran, R., Brigden, A., Linney, C., McManus, M., Borwick, C., \& Crawley, E. (2020). Rapid Review: The impact of social isolation and loneliness on the mental health of children and adolescents in the context of COVID-19. Journal of the American Academy of Child and Adolescent Psychiatry. https://doi.org/None Luchetti, M., Lee, J. H., Aschwanden, D., Sesker, A., Strickhouser, J. E., Terracciano, A., \& Sutin, A. R. (2020). The trajectory of loneliness in response to COVID-19. American Psychologist. https://doi.org/10.1037/amp0000690

Ma, R., Mann, F., Wang, J., Lloyd-Evans, B., Terhune, J., Al-Shihabi, A., \& Johnson, S. (2020). The effectiveness of interventions for reducing subjective and objective social isolation among 
people with mental health problems: A systematic review. Social Psychiatry and Psychiatric Epidemiology, 55(7), 839-876. https://doi.org/10.1007/s00127-019-01800-z

Mahon, N. E., Yarcheski, A., Yarcheski, T. J., Cannella, B. L., \& Hanks, M. M. (2006). A Meta-analytic Study of Predictors for Loneliness During Adolescence. Nursing Research, 55(5), 308-315.

Martin, R. C., \& Dahlen, E. R. (2005). Cognitive emotion regulation in the prediction of depression, anxiety, stress, and anger. Personality and Individual Differences, 39(7), 1249-1260. https://doi.org/10.1016/j.paid.2005.06.004

Masi, C. M., Chen, H.-Y., Hawkley, L. C., \& Cacioppo, J. T. (2011). A Meta-Analysis of Interventions to Reduce Loneliness. Personality and Social Psychology Review : An Official Journal of the Society for Personality and Social Psychology, Inc, 15(3). https://doi.org/10.1177/1088868310377394

Mata, J., Wenz, A., Rettig, T., Reifenscheid, M., Moehring, K., Krieger, U., Friedel, S., Fikel, M., Cornesse, C., Blom, A. G., \& Naumann, E. (2020). Health behaviors and mental health before and during the COVID-19 pandemic: A longitudinal population-based survey [Preprint]. PsyArXiv. https://doi.org/10.31234/osf.io/qbgh7

Matthews, T., Danese, A., Wertz, J., Odgers, C. L., Ambler, A., Moffitt, T. E., \& Arseneault, L. (2016). Social isolation, loneliness and depression in young adulthood: A behavioural genetic analysis. Social Psychiatry and Psychiatric Epidemiology, 51(3), 339-348. https://doi.org/10.1007/s00127-016-1178-7

Nolen-Hoeksema, S., Girgus, J. S., \& Seligman, M. E. (1992). Predictors and consequences of childhood depressive symptoms: A 5-year longitudinal study. Journal of Abnormal Psychology, 101(3), 405-422. https://doi.org/10.1037/0021-843X.101.3.405

Novotny, J. S., Rivas, J. P. G., Kunzova, S., Skladana, M., Pospisilova, A., Polcrova, A., Inojosa, J. R. M., Lopez-Jimenez, F., Geda, Y. E., \& Stokin, G. B. (2020). Association between stress and depressive symptoms and the Covid-19 pandemic. MedRxiv, 2020.07.28.20163113. https://doi.org/10.1101/2020.07.28.20163113

Palgi, Y., Shrira, A., Ring, L., Bodner, E., Avidor, S., Bergman, Y., Cohen-Fridel, S., Keisari, S., \& Hoffman, Y. (2020). The loneliness pandemic: Loneliness and other concomitants of depression, anxiety and their comorbidity during the COVID-19 outbreak. Journal of Affective Disorders, 275, 109-111. https://doi.org/10.1016/j.jad.2020.06.036

Pels, F., \& Kleinert, J. (2016). Loneliness and physical activity: A systematic review. International Review of Sport and Exercise Psychology, 9(1), 231-260.

https://doi.org/10.1080/1750984X.2016.1177849

Perlman, D. and Peplau, L. A. (1981) Toward a social psychology of loneliness. In R. Gilmour, \& S. Duck (Eds.), Personal relationships in disorder (pp. 31-56), London: Academic Press. 
Pierce, M., Hope, H., Ford, T., Hatch, S., Hotopf, M., John, A., Kontopantelis, E., Webb, R., Wessely, S., McManus, S., \& Abel, K. M. (2020). Mental health before and during the COVID-19 pandemic: A longitudinal probability sample survey of the UK population. The Lancet Psychiatry, 7(10), 883-892. https://doi.org/10.1016/S2215-0366(20)30308-4

Restubog, S. L. D., Ocampo, A. C. G., \& Wang, L. (2020). Taking control amidst the chaos: Emotion regulation during the COVID-19 pandemic. Journal of Vocational Behavior, 119, 103440. https://doi.org/10.1016/j.jvb.2020.103440

Robertson, R., Robertson, A., Jepson, R., \& Maxwell, M. (2012). Walking for depression or depressive symptoms: A systematic review and meta-analysis. Mental Health and Physical Activity, 5(1), 66-75. https://doi.org/10.1016/j.mhpa.2012.03.002

Salerno, J. P., Williams, N. D., \& Gattamorta, K. A. (2020). LGBTQ populations: Psychologically vulnerable communities in the COVID-19 pandemic. Psychological Trauma: Theory, Research, Practice, and Policy, 12(S1), S239. https://doi.org/10.1037/tra0000837

Santini, Z. I., Jose, P. E., York Cornwell, E., Koyanagi, A., Nielsen, L., Hinrichsen, C., Meilstrup, C., Madsen, K. R., \& Koushede, V. (2020). Social disconnectedness, perceived isolation, and symptoms of depression and anxiety among older Americans (NSHAP): A longitudinal mediation analysis. The Lancet Public Health, 5(1), e62-e70. https://doi.org/10.1016/S24682667(19)30230-0

Stathopoulou, G., Powers, M. B., Berry, A. C., Smits, J. A. J., \& Otto, M. W. (2006). Exercise Interventions for Mental Health: A Quantitative and Qualitative Review. Clinical Psychology: Science and Practice, 13(2), 179-193. https://doi.org/10.1111/j.1468-2850.2006.00021.x

Steptoe, A., Shankar, A., Demakakos, P., \& Wardle, J. (2013). Social isolation, loneliness, and allcause mortality in older men and women. Proceedings of the National Academy of Sciences, 110(15), 5797-5801. https://doi.org/10.1073/pnas.1219686110

Ullman, J. B. (2001). "Structural Equation Modeling," in Using Multivariate Statistics, 5th Edn., eds B.G Tabachnick and L. S Fidell. Boston, MA: Allyn \& Bacon.

van Tilburg, T. G., Steinmetz, S., Stolte, E., van der Roest, H., \& de Vries, D. H. (n.d.). Loneliness and Mental Health During the COVID-19 Pandemic: A Study Among Dutch Older Adults. The Journals of Gerontology: Series B. https://doi.org/10.1093/geronb/gbaa111

Vanhalst, J., Luyckx, K., Raes, F., \& Goossens, L. (2012). Loneliness and depressive symptoms: The mediating and moderating role of uncontrollable ruminative thoughts. The Journal of Psychology, 146(1-2), 259-276. https://doi.org/10.1080/00223980.2011.555433 
Vanhalst, J., Luyckx, K., Teppers, E., \& Goossens, L. (2012). Disentangling the Longitudinal Relation Between Loneliness and Depressive Symptoms: Prospective Effects and the Intervening Role of Coping. Journal of Social and Clinical Psychology, 31(8), 810-834. https://doi.org/10.1521/jscp.2012.31.8.810

Wang, C., Pan, R., Wan, X., Tan, Y., Xu, L., Mclntyre, R. S., Choo, F. N., Tran, B., Ho, R., Sharma, V. K., \& Ho, C. (2020). A longitudinal study on the mental health of general population during the COVID-19 epidemic in China. Brain, Behavior, and Immunity, 87, 40-48. https://doi.org/10.1016/j.bbi.2020.04.028

Weeks, D. G., Michela, J. L., Peplau, L. A., \& Bragg, M. E. (1980). Relation between loneliness and depression: A structural equation analysis. Journal of Personality and Social Psychology, 39(6), 1238-1244. https://doi.org/10.1037/h0077709

Wei, M., Russell, D. W., \& Zakalik, R. A. (2005). Adult Attachment, Social Self-Efficacy, Self-Disclosure, Loneliness, and Subsequent Depression for Freshman College Students: A Longitudinal Study. Journal of Counseling Psychology, 52(4), 602-614. https://doi.org/10.1037/00220167.52.4.602

Weinert, C., Cudney, S., \& Hill, W. G. (2008). Rural Women, Technology, and Self-Management of Chronic Illness. The Canadian Journal of Nursing Research = Revue Canadienne de Recherche En Sciences Infirmieres, 40(3), 114-134.

Weiss, R. S. (1973). Loneliness: The experience of emotional and social isolation. Cambridge, MA: MIT Press.

WHO. (2020). Mental health and psychosocial considerations during the COVID-19 outbreak (WHO/2019-nCoV/MentalHealth/2020.1). World Health Organisation.

Wols, A., Scholte, R. H. J., \& Qualter, P. (2015). Prospective associations between loneliness and emotional intelligence. Journal of Adolescence, 39, 40-48. https://doi.org/10.1016/j.adolescence.2014.12.007

Wright, L., Steptoe, A., \& Fancourt, D. (2020). Are we all in this together? Longitudinal assessment of cumulative adversities by socioeconomic position in the first 3 weeks of lockdown in the UK. J Epidemiol Community Health, 74(9), 683-688. https://doi.org/10.1136/jech-2020-214475

Zawadzki, M. J., Graham, J. E., \& Gerin, W. (2013). Rumination and anxiety mediate the effect of loneliness on depressed mood and sleep quality in college students. Health Psychology: Official Journal of the Division of Health Psychology, American Psychological Association, 32(2), 212-222. https://doi.org/10.1037/a0029007 